\title{
Warisan Air Panas Kaliulo sebagai Campuran dalam Memasak bagi Penduduk Kecamatan Pringapus Kabupaten Semarang Jawa Tengah
}

\author{
Suharwanto \\ Jurusan Teknik Lingkungan, Fakultas Teknologi Mineral, UPN "Veteran” Yogyakarta, \\ Jl. SWK 104 (Lingkar Utara), Condongcatur, Yogyakarta, 55283 \\ E-mail korespondensi :Harwanto_upn@yahoo.com
}

\begin{abstract}
ABSTRAK
Mata Air panas di Kaliulo Pringapus Semarang Jawa Tengah secara turun temurun telah dimanfaatkan oleh beberapa penduduk sebagai bahan campuran dalam memasak, misalnya membuat kerupuk dan merebus bahan makanan (seperti membuat ketupat). Hasil memasak selain untuk konsumsi sendiri juga dijual di pasar terdekat. Ketika musim kemarau tiba, air panas Kaliulo tidak hanya untuk bahan campuran memasak akan tetapi juga dikonsumsi untuk air minum. Dengan demikian perlu adanya analisis kandungan zat-zat yang ada secara fisik maupun kimia untuk mengetahui kualitas air panas tersebut. Peninjauan kualitas air panas mengacu pada kualitas air minum dengan standar ambang batas sesuai dengan peraturan pemerintah nomor 82 tahun 2001 tentang pengelolaan kualitas air dan pengendalian pencemaran air. Analisis yang dilakukan terdiri dari analisis fisik dan kimia. Untuk analisis fisik meliputi suhu dan DHL, sedangkan analisis kimia meliputi $\mathrm{pH}$, konsentrasi $\mathrm{SiO}_{2}, \mathrm{Al}_{\text {, }}$ $\mathrm{Fe}, \mathrm{Ca}, \mathrm{Mg}, \mathrm{Na}, \mathrm{K}, \mathrm{Li}, \mathrm{Mn}, \mathrm{NH}_{3}, \mathrm{Cl}, \mathrm{SO}_{4}, \mathrm{HCO}_{3}, \mathrm{~B}$ dan $\mathrm{H}_{2} \mathrm{~S}$. Kadar $\mathrm{NaCl}, \mathrm{H}_{2} \mathrm{~S}$ dan $\mathrm{NH}_{3}$ dalam air panas ternyata melebihi ambang batas persyaratan untuk air minum.
\end{abstract}

Kata kunci: Air Panas

\section{ABSTRACT}

Kaliulo hot spring is located at Pringapus, Semarang District, Central Java. The hot spring has been used for cooking mixture by society like making krupuk (cracker) and ketupat. The result of cooking is used for consumption of the citizens themselves and for being sold to market. In the dry season, Kaliulo hot spring is not only for mixturing in cooking but also for drinking. Physical and chemistry analysis must be done to know the water quality. The quality of water based on the drinking water quality with standard from the government regulation number 82 / 2001 about water quality management and water pollution prevention. The physical analysis consists of temperature and DHL (conductivity), meanwhile chemical analysis consists of pH, $\mathrm{SiO}_{2}, \mathrm{Al}, \mathrm{Fe}, \mathrm{Ca}, \mathrm{Mg}, \mathrm{Na}, \mathrm{K}$, $\mathrm{Li}, \mathrm{Mn}, \mathrm{NH}_{3}, \mathrm{Cl}, \mathrm{SO}_{4}, \mathrm{HCO}_{3}, \mathrm{~B}$ dan $\mathrm{H}_{2} \mathrm{~S}$. The content of $\mathrm{Na}, \mathrm{Cl}, \mathrm{H}_{2} \mathrm{~S}$ and $\mathrm{NH}_{3}$ in hot spring is exceed normally standard for drinking.

Keyword: Hot Spring

\section{PENDAHULUAN}

Air Panas Kaliulo Kecamatan Pringapus Kabupaten Semarang secara turun temurun telah dimanfaatkan oleh penduduk sekitar Kaliulo sebagai bahan campuran dalam memasak, antara lain membuat kerupuk dan memasak ketupat. Masakan yang dihasilkan sebagian kecil di konsumsi sendiri sedangkan bagian yang lebih besar umumnya mereka jual kemasyarakat umum di Pasar Kecamatan Pringapus Kabupaten Semarang Jawa Tengah. Pada saat musim kemarau tiba daerah sekitar mata air panas Kaliulo mengalami kekeringan sedangkan mata air panas Kaliulo tetap keluar air nya meski debitnya menurun, sehingga air panas Kaliulo selain dimanfaatkan sebagai bahan campuran dalam memasak, juga sebagai sumber air 
minum. Dan pada musim penghujan debit mata air panas Kaliulo membesar lagi. Permasalahan yang muncul antara lain sejauhmana pengaruh pemanfatan air panas Kaliulo oleh penduduk terhadap kesehatan ditinjau dari kandungan kimia dalam air panas tersebut.

\section{METODE PENELITIAN}

Penelitian dilakukan dengan cara pengumpulan data primer dan data sekunder. Data primer berupa survei dan pemetaan geologi, pengukuran sifat fisik air, dan pengambilan contoh air panas untuk analisa kimia air dan mikrobiologi serta wawancara langsung dengan penduduk. Sedangkan pengumpulan data sekunder terdiri dari kajian pustaka dan data-data hasil penelitian terdahulu.

\section{A. Geologi}

Lokasi penelitian termasuk dalam wilayah Kecamatan Priangapus Kabupaten Semarang Jawa tengah yang secara geologi regional terletak pada Stratigrafi Ungaran. Menurut De Genevraye dan Samuel (1972), Stratigrafi Ungaran secara regional terdiri dari beberapa Formasi dari lapisan tua ke muda sebagai berikut: Formasi Pelang, Formasi Kerek, Formasi Banyak, Formasi Cipluk, Formasi Anggota Kapung, Formasi Kalibeng, Formasi Kalibeng Anggota Kapung, Formasi Damar, Formasi Kaligetas, Satuan Endapan Vulkanik Muda, Endapan Aluvial. Adapun batuan yang tersingkap di sekitar mata air panas Kaliulo adalah satuan batupasir Formasi Banyak (perselingan batupasir dengan batupasir tufan, batupasir kerikilan, batupasir gampingan, sesipan batulempung dan napal) yang secara tidak selaras ditutupi oleh Satuan Breksi Vulkanik Kaligetas (breksi vulaknik berfragmen andesit dan basalt dengan sisipan batupasir tufan).Di sekitar mata air panas dijumpai zona hancur (breksiasi) pada satuan batupasir Formasi banyak yang memiliki kelurusan $\mathrm{N} 15^{\circ}$ E. Diinterpretasikan bahwa munculnya mata air panas berkait erat dengan adanya proses pensesaran daerah Kaliulo. Kondisi mata air Kaliulo adalah sesuai pada Gambar 1.

\section{B. Survei dan Pemetaan Geologi}

Survei dan pemetaan dilakukan dengan cara pengamatan singkapan batuan, mendiskripsi batuan, mengukur kedudukan batuan, mengamati urut-urutan stratigrafi, mengamati dan mengukur unsur-unsur struktur, merekam data pada buku lapangan ataupun mengeplotkan langsung pada peta. Peralatan yang dipergunakan adalah peta rupa bumi daerah telitian skala 1: 25.000, kompas geologi, palu geologi, buku catatan lapangan, busur derajad, penggaris dan alat tulis, HCL $0.5 \mathrm{~N}$ dan kantong contoh batuan.

\section{Pengukuran Sifat Fisik Air}

Pengukuran temperature dilakukan dengan memasukkan thermometer kebagian tengah tempat keluarnya mata air. Untuk mendapatkan temperatur yang sebenarnya maka perlu dilakukan pengukuran berulang kali hingga mencapai hasil yang stabil. Peralatan yang dipergunakan adalah thermometer, water sampling equipment, curentmeter. Untuk mengetahui debit air, maka terlebih dahulu diukur kecepatan arusnya dengan mempergunakan curentmeter. Perhitungan perkalian dari volume air yang mengalir terhadap kecepatannya merupakan debit air tersebut. 


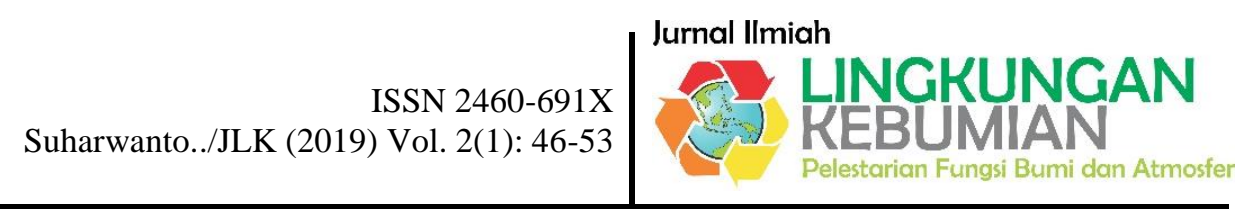

\section{Pengambilan contoh air panas}

Pengambilan contoh air dilakukan pada bagian tengah tempat keluarnya mata air dengan mempergunakan water sampling equipment. Lalu contoh air dimasukkan dalam botol steril dan segera dibawa ke laboratorium kimia air.

\section{E. Analisa Kimia Air}

Analisa kimia air dilakukan di laboratorium kimia air dengan bahan dan peralatan berupa: reagen (larutankimia), gelas beker, pipet, spektrofotometer, buret, alatfiltrasi, instrumen timbangan.

\section{F. Analisa mikrobiologi}

Sebelum mengambil contoh air panas tangan dibersihkan dulu dengan alcohol atau bisa juga dengan "antis". Prinsipnya untuk mendeteksi keberadaan bakteri dan sekaligus menaksir konsentrasinya. Metoda yang akan dipakai adalah standard plate count (SPC). Bahan yang diperlukan adalah Autoklap untuk sterilisasi/ alkohol/ antis, Alat penghitung koloni (colony counter) jenis Quebec, TIP (ujung) pipet 100-100 mikron liter, alat timbangan (dengan telitian sampai $0.1 \mathrm{mg}$ ), aluminium foil, inkubator. Metoda terakhir adalah peninjauan kualitas mata air panas mengacu pada Peratutan Pemerintah $82 \mathrm{Th}$ 2001. Tentang Pengelolaan Kualitas Air Dan Pengendalian Pencemaran Air.

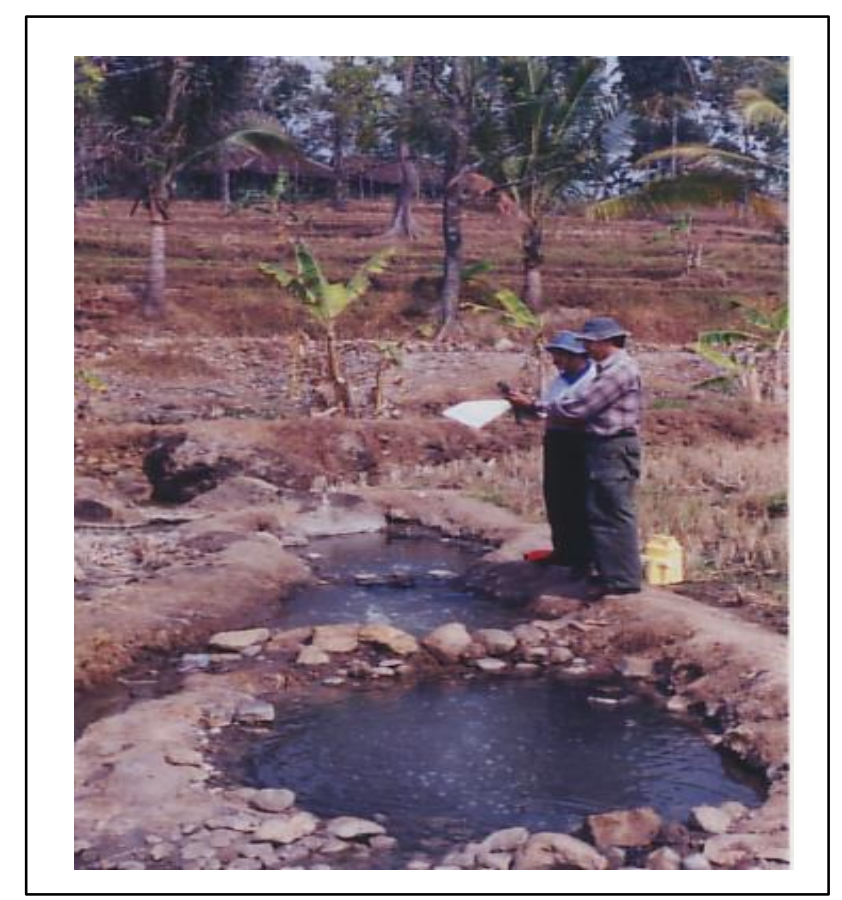

Gambar 1. Mata air panas Kaliulo, Kecamatan Pringapus, Jawa Tengah. 

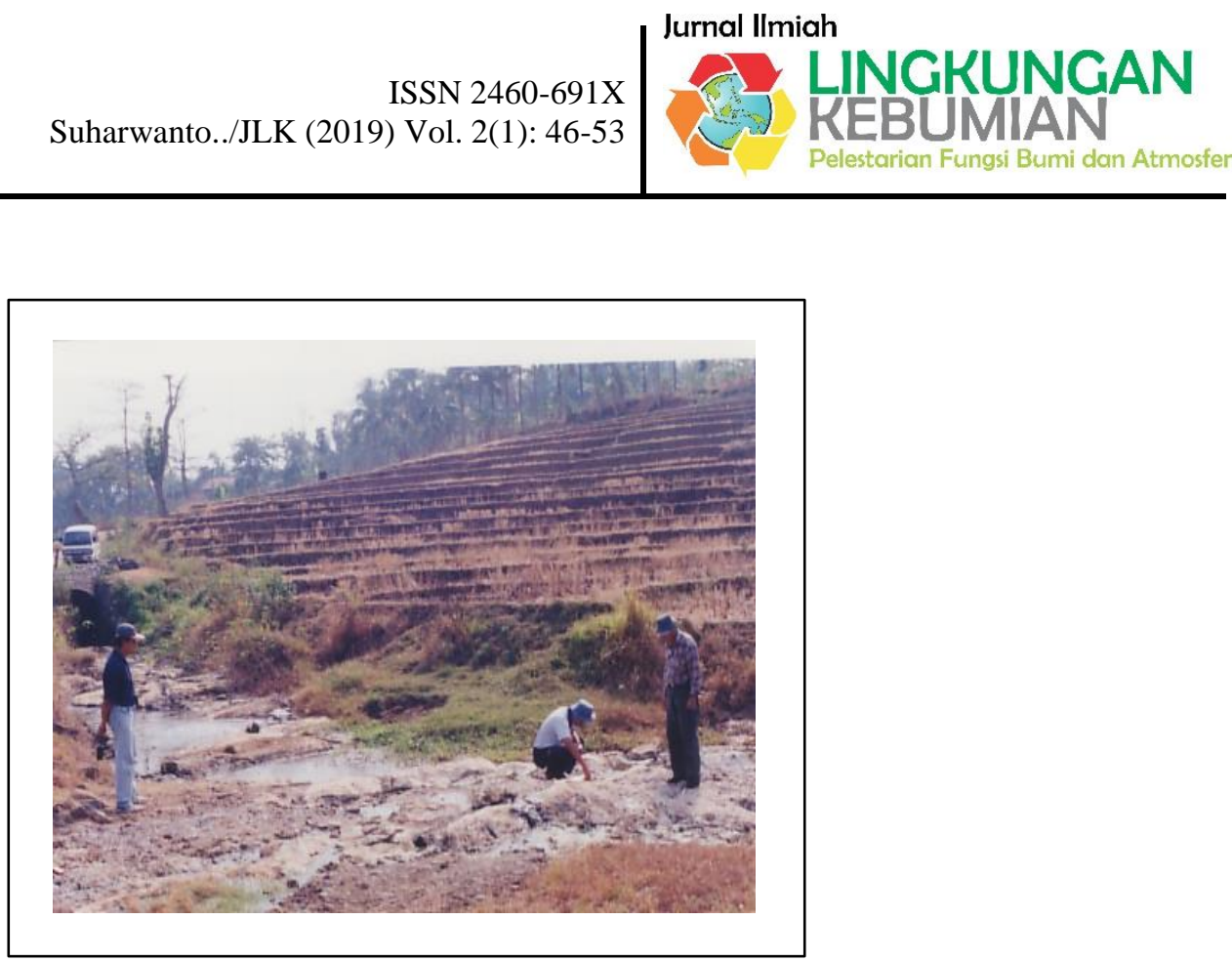

Gambar 2. Singkapan perselingan batupasir dengan batupasir tufan sisipan batulempung.

HASIL PENELITIAN

A. Kualitas Air panas Kaliulo

Tabel 1. Analisis Kimia Air panas Kaliulo

\begin{tabular}{lc}
\hline \multicolumn{1}{c}{ Unsur } & Konsentrasi (ppm) \\
\hline $\mathrm{SiO}_{2}$ & 20.06 \\
\hline $\mathrm{Al}$ & 0 \\
\hline $\mathrm{Fe}$ & 50.13 \\
\hline $\mathrm{Ca}$ & 27.85 \\
\hline $\mathrm{Mg}$ & 874 \\
\hline $\mathrm{Na}$ & 271.9 \\
\hline $\mathrm{K}$ & 1.68 \\
\hline $\mathrm{Li}$ & 0 \\
\hline $\mathrm{Mn}$ & 18.56 \\
\hline $\mathrm{NH}_{3}$ & 551.94 \\
\hline $\mathrm{Cl}$ & 8.87 \\
\hline $\mathrm{SO}_{4}$ & 3006.12 \\
\hline $\mathrm{HCO}_{3}$ & 81.13 \\
\hline $\mathrm{B}$ & 12,73 \\
\hline $\mathrm{H}_{2} \mathrm{~S}$ & \\
\hline
\end{tabular}


Tabel 2. Keterdapatan mata air panas Kaliulo.

\begin{tabular}{cccccc}
\hline Lokasi & Mnifestasi & $\begin{array}{c}\text { Suhu } \\
\left({ }^{\circ} \mathbf{C}\right)\end{array}$ & $\begin{array}{c}\text { pH } \\
\text { Kaliulo }\end{array}$ & $\begin{array}{c}\text { Debit } \\
(\mathbf{l} / \mathbf{d t})\end{array}$ & Keterangan \\
\hline Kolam air panas & 39,4 & 7 & 0.15 & $\begin{array}{l}\text { Terdapat adanya ubahan batuan } \\
\text { berupa travertin dengan luas 120 m2, } \\
\text { dijumpai pula gelembung-gelembung } \\
\text { gas. }\end{array}$ \\
\hline
\end{tabular}

Pada Pasal 8 Peraturan Pemerintah No. 82 Tahun 2001 Tentang Pengelolaan Kualitas Air dan Pengendalian Pencemaran Air dijelaskan tentang adanya klasifikasi mutu air, yang dibedakan ke dalam 4 (empat) kelas.

Oleh karena mata air panas Kaliulo Pringapus dimanfaatkan sebagai campuran dalam memasak dan bahkan air minum (di musim kemarau), maka kriteria mutu air yang dipersyaratkan adalah termasuk dalam kelas I (satu).

Hasil analisis kimia air panas Kaliulo (lihat Tabel 1) terlihat bahwa tidak terdapat kandungan AL, Fe maupun $\mathrm{Mn}(0 \mathrm{mg} / \mathrm{l})$. Kadar $\mathrm{Na}$ dan $\mathrm{Cl}$ dalam air panas sebesar $874 \mathrm{mg} / \mathrm{l}$ dan $551 \mathrm{mg} / \mathrm{l}$, dimana kadar tersebut cukup tinggi untuk air minum. Dengan kandungan $\mathrm{Na}$ dan $\mathrm{Cl}$ dapat diketahui bahwa terdapat larutan garam $\mathrm{NaCl}$ dalam air panas. Dengan adanya larutan garam $\mathrm{NaCl}$ yang tinggi, apabila dipergunakan untuk merebus/memasak membuat masakan tersebut terasa asin.

Dan dapat diketahui pula untuk kadar $\mathrm{NH}_{3}$ (Amoniak) sebesar 18,56 mg/l dimana kadar tersebut melebihi ambang batas $(0,5 \mathrm{mg} / \mathrm{l})$. Amoniak $\left(\mathrm{NH}_{3}\right)$ dalam airpanas akan teroksidasi menjadi nitrit dan selanjutnya teroksidasi kembali menjadi nitrat. Apabila nitrit dan nitrat yang ada dalam air melebihi ambang batas dapat mengakibatkan gangguan kesehatan.

Sedangkan untuk kadar $\mathrm{SO}_{4}$ sebesar $8,87 \mathrm{mg} / \mathrm{l}$ dimana masih berada dibawah ambang batas yang diijinkan yaitu sebesar $400 \mathrm{mg} / \mathrm{l}$. Dan untuk kadar $\mathrm{H}_{2} \mathrm{~S}$ (sulfida) sebesar 12,73 mg/l lebih tinggi dari ambang batas $(0,002 \mathrm{mg} / \mathrm{l})$. Hidrogen Sulfida $\left(\mathrm{H}_{2} \mathrm{~S}\right)$ terdapat dalam air panas merupakan hasil reduksi sulfat di kawah gunung berapi. Kelebihan $\mathrm{H}_{2} \mathrm{~S}$ dalam air minum berakibat bau tidak sedap (seperti bau telur busuk) dan apabila bernafas dalam udara dengan kandungan $\mathrm{H}_{2} \mathrm{~S}$ lebih dari 0,005\% dalam waktu singkat menyebabkan keracunan kuat

\section{B. Kualitas Air dan Permasalahan Kesehatan}

\section{Kelebihan Unsur Besi $(\mathrm{Fe})$}

Pemanfaatan air sebagai campuran dalam memasak maupun pengolahan air minum secara konvensional yang dibolehkan adalah kadar $\mathrm{Fe} \leq 5 \mathrm{mg} / \mathrm{L}$. Air yang banyak mengandung unsur besi lebih dari $5 \mathrm{mg} / \mathrm{l}$ tidak dibernarkan untuk air minum. Memang selama ini belum ada penelitian yang menunjukkan adanya gangguan kesehatan yang ditimbulkan oleh zat besi. Namun demikian air yang terlalu banyak mengandung unsur ini akan berbau anyir dan berwarna keruh. Air yang terlalu banyak mengandung unsur besi juga tidak baik digunakan untuk air bersih khususnya bila digunakan untuk 
mencuci. Pakaian yang terlalu sering dicuci dengan air berkadar besi tinggi lama kelamaan akan berubah warnanya menjadi kekuning-kuningan

\section{Kelebihan unsur Mangan (Mn)}

Mangan adalah koenzim di dalam reaksi mitokondrial. Zat ini merupakan nutrien jejak esensial. Kekurangan unsur di dalam tubuh persyaratan nutrisi di dalam tubuh tidak stabil. Akan tetapi keracunan Mn dapat mengakibatkan orang selalu mengantuk, mudah terkena kram (kejang) kaki, linu persendian dan gangguan emosional. Batas yang disarankan adalah $0.05-0.1 \mathrm{mg} / \mathrm{l}$.

\section{Kelebihan Unsur Kalsium (Ca)}

Kelebihan unsur kalsium selama ini tidak diketahui dampak kesehatan yang ditimbulkannya. Namun demikian kandungan unsur kalsium di dalam air minum sebaiknya tidak melebihi ambang yang dipersyaratkan oleh departemen kesehatan, sebab disinyalir ada hubungan erat antara penyakit kardiovaskuler dengan konsumsi kalsium yang berlebihan. Ambang batas unsur kalsium adalah 75 $\mathrm{mg} / \mathrm{l}$.

\section{Kelebihan Unsur Magnesium (Mn)}

Sebagaimana halnya klasium, kelebihan unsur magnesium juga tidak diketahui dampak kesehatan yang ditimbulkannya. Namun demikian kandungan unsur magnesium di dalam air minum sebaiknya tidak melebihi ambang yang dipersyaratkan oleh departemen kesehatan, sebab disinyalir ada hubungan erat antara penyakit kardiovaskuler.

\section{Kelebihan Unsur Natrium Klorida $(\mathrm{NaCl})$}

Air tanah yang mengandung unsur $\mathrm{Na}$ dan $\mathrm{Cl}$ melebihi batas toleransi selain menimbulkan rasa asin, dapat memperparah penyakit tekanan darah tinggi, jika dikonsumsi terus menerus. Air yang mengandung terlalu banyak $\mathrm{Cl}$ juga disinyalir dapat mengakibatkan timbulnya penyakit hepatitis. Batas toleransi kandungan $\mathrm{Cl}$ adalah $250 \mathrm{mg} / \mathrm{l}$.

\section{Kelebihan Nitrat $\left(\mathrm{NO}_{3}\right)$}

Kelebihan nitrat di dalam tubuh wanita hamil dapat menimbulkan methamoglobinemia atau penyakit "blue baby",yaitu bayi yang dilahirkan berwarna ke biru-biruan. Selain itu nitrat juga dapat menyebabkan kanker tulang, gangguan pada jantung dan tekanan darah tinggi (Drinking water and Helth, 1977). Batas toleransi kandungan nitrat adalah $10.0 \mathrm{mg} / 1$.

\section{Kelebihan Nitrit $\left(\mathrm{NO}_{2}^{-}\right)$}

Senyawa nitrit sangat beracun bagi manusia, akibat mengkonsumsi terlalu banyak nitrit dapat menyebabkan kematian.

\section{Kelebihan Sulfat $\left(\mathrm{SO}_{4}\right)$}

Kelebihan sulfat belum diketahui dampak kesehatan yang ditimbulkannya. Namun demikian dianjurkan untuk mengkonsumsi air dengan kandungan sulfat yang tidak melebihi standar kualitas air minum. 


\section{Kandungan Deterjen}

Deterjen di dalam air minum bersifat racun. Konsentrasi melebihi batas toleransi di dalam air minum dapat mengakibatkan gangguan kesehatan. Batas toleransi kandungan deterjen adalah $0.05 \mathrm{mg} / \mathrm{l}$.

\section{Kandungan Bakteri Koli}

Entamoueba coli (amuba coli) merupakan salah satu mikroorganisme berbahaya bagi kesehatan yang hidup di dalam air. Koli tinja banyak terdapat pada kotoran manusia atau binatang. Organisme ini dapat masuk ke air tanah apabila air tanah tercemari oleh kotoran yang berasal dari tempat-tempat pembuangan misalnya septik tank. Apabila air yang mengandung bakteri koli tinja diminum tanpa direbus, dapat mengakibatkan penyakit perut, desentri, muntaber dsb. Standar air minum tidak mengandung bakteri koli, apalagi koli tinja. Koli tinja dapat mengakibatkan penyakit perut seperti mulas-mulas, diare, desentri, muntaber, dll. Cara mengatasi air yang mengandung bakteri koli adalah dengan direbus terlebih dahulu hingga mendidih dan dibiarkan selama kurang lebih 3 menit. Sebelum diminum. Air minum seharusnya tidak mengandung bakteri koli (0 MPN/ $100 \mathrm{ml}$ ).

\section{Dampak lain yang ditimbulkan oleh pencemaran air :}

Disebabkan oleh mineral:

1. Cd (Cadmium)

Dapat menyebabkan kerusakan pada ginjal, hati, tulang, pankreas, kelenjar gondok.

2. $\mathrm{Cu}$ (Tembaga)

Dalam jumlah besar menyebabkan rasa tidak enak di lidah dan menimbulkan kerusakan pada ginjal dan hati.

3. $\mathrm{Pb}$ (Timahhitam)

Bersifat kronis dan kumulatif. Keracunan $\mathrm{Pb}$ menimbulkan anemia, gangguan ginjal, penurunan mental padaanak-anak.

4. $\mathrm{Hg}$ (merkuri)

Merupakan unsur yang sangat beracun. Pada keracunan tingkat ringan timbul pusing, sakit kepala, mudah lelah. Pada keracunan tingkat berat menyebabkan kerusakan ginjal, sendi-sendi kaku, penglihatan terganggu, kelainan sistem syaraf dan dapat menyebabkan kematian.

5. Asbes

Asbes dalam air minum akan menyebabkan asbestosis.

6. Se (selenium)

Menyebabkan radang usus dan kerusakan pada jaringan.

\section{KESIMPULAN}

Adapun kesimpulan yang diperoleh adalah Air panas pada mata air Kaliulo tidak layak untuk air minum ataupun sebagai pencampur dalam memasak. 


\section{DAFTAR PUSTAKA}

Alaert,G., Santika.S.S., 1987, MetodaPenelitian Air, Penerbit “Usaha Nasional” Surabaya-Indonesia.

Darmono, 2008 : Lingkungan Hidup dan Pencemaran Hubungan Dengan Toksikologi Senyawa Logam, UI Press Jakarta.

Laporan Hasil Penelitian, 2002: Potensi Sumberdaya Alam Kabupaten Semarang, Lembaga Penelitian UPN "Veteran" Yogyakarta.

Mukono, H.J 200: Prinsip Dasar Kesehatan Lingkungan, Airlangga University Press. Peraturan Pemerintah Nomor 82 Tahun 2001, tentang Pengelolaan Kualitas Air dan Pengendalian Pencemaran Air. 